\title{
Experimental study to harvest energy from asphalt roadways
}

\begin{abstract}
This paper presents preliminary results of the evaluation of several prototype systems for harvesting energy from the action of traffic on roadways. These systems utilize piezoelectric elements that respond to traffic-induced compressive stresses, and are referred to as HiSEC (Highway Sensing and Energy Conversion) modules. The evaluation of the HiSEC prototypes involves laboratory testing of their power output as a function of stress, finite element (FE) simulation of their mechanical behavior and economic analysis of the value of the power being generated. The results available to date suggest that this technology shows promise in powering equipment independently of the power grid.
\end{abstract}

Volume I Issue 3 - 2016

\author{
Hossein Roshani,' SamerDessouky, ${ }^{2}$ \\ Papagiannakis $\mathrm{AT}^{3}$ \\ 'Graduate Research Assistant, Civil Engineering department, \\ University of Texas at San Antonio, USA \\ ${ }^{2}$ Associate Professor, Civil Engineering department, University of \\ Texas at San Antonio, USA \\ ${ }^{3}$ Department of Civil Engineering, University of Texas at San \\ Antonio, USA
}

\begin{abstract}
Correspondence: Samer Dessouky, Department of Civil and Environmental Engineering, University of Texas at San Antonio, BSE BIdg. 1.322, One UTSA Circle, San Antonio, TX 78249, USA, Email samer.dessouky@utsa.edu
\end{abstract}

Received: October 20, 2016 | Published: November 25, 2016
Abbreviations: HISEC, highway sensing and energy conversion; LCOE, levelized cost of energy; FE, finite element

\section{Introduction}

In recent years, there has been increasing interest in energy harvesting through transduction. Three technologies have been used for this purpose, namely electromagnetic, electrostatic and piezoelectric $^{0}$. Piezoelectric transduction appears to be the most promising, given its widest power density versus voltage envelop, as shown in Figure 1. A number of recent studies explored the use of piezoelectric transduction for harvesting energy from roadways, e.g, ${ }^{1-3}$ Work by Xiong 2014 at Virginia Tech produced a piezoelectric harvesting system consisting of multiple cylindrical piezoelectric elements that are compressed by the action of traffic tires Figure 2. Under a traffic volume of 4,000 vehicle per day (167 vehicles/hour), this system generated voltage ranging from 400 to $700 \mathrm{~V}$ and electric currents ranging from 0.2 to $0.35 \mathrm{~mA}$. The corresponding power output was obtained by multiplying voltage by current, yielding a power range between 0.08 and 2.1 Watts per system. Work by Kim et $\mathrm{al}^{2}$ at Georgia Southern University involved laboratory testing using an Asphalt Pavement Analyzer (APA). Two piezoelectric materials were tested one manufactured by Noliac and the other by Kinetic. APA wheel loads at three levels were applied, namely 50, 100 and $200 \mathrm{lbs}$. The maximum resulting voltages for the Noliac were 5 , 5, and 15 Volts, respectively, while for the Kinetic were 5, 10 and 20Volts, respectively. Assuming a traffic level of 600 vehicles/hour at a speed of $45 \mathrm{mph}$, such a system could produce up to $2.67 \mathrm{~mW}$ of power. Zhao et al. ${ }^{3}$ at Tongji University studied power generation form several types of piezoelectric sensor configurations. These included multiple lead zirconatetitanate (i.e., PZT) prismatic elements referred to as "piles" with circular, square or hexagonal cross sections, as well as commercially available cymbal-shaped and bridge-shaped elements Figure 3. They performed FE analysis to study the effect of the shape of the PZT piles in producing electric power output, concluding that the circular cross section piles were preferable. Power generators involving multiple piles were analyzed. Stress analysis combined with theoretical calculations established that generators with 8-16 piles each can be used to harvest significant amounts of electrical power under heavy traffic.

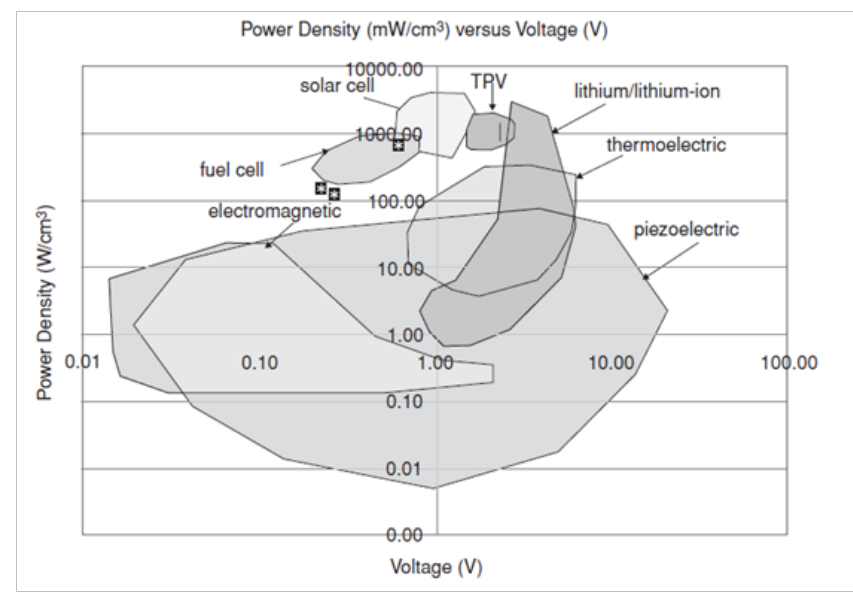

Figure I Power density versus voltage for various energy harvesting technologies."

A report was recently completed on behalf of the California Energy Commission (CEC) to independently evaluate the feasibility of piezoelectric technology in harvesting energy from roadways and establish if this technology warrants further study. ${ }^{4}$ It evaluated some of the pilot systems developed by Universities, as well as commercially available harvesting systems. Three commercially available systems were evaluated in terms of their vendor output claims, namely, Treevolt, ${ }^{5}$ Genziko $^{6}$ and Innowattech. ${ }^{7}$ The first two of these three vendors appear to continue development of this technology. The Treevolt harvesters, marketed in the USA under the Power Leap name, consist of recycled butyl-propelene membranes sandwiching sheets of harvesting devices are embedded under the top layer of asphalt concrete and are activated in compression. The 
vendor claims that $1.0 \mathrm{~km}$ length of roadway equipped with 6,000 Treevolt harvesters and carrying 600 vehicles per hour can generate approximately $720 \mathrm{~kW}$ of power. Genziko claims that under the same traffic level, their vibration-activated harvesters have the potential to generate a considerably higher $13,600 \mathrm{~kW}$ of power, an amount that was considered "optimistic" by the CEC report. Innowattech claims that their harvesters can generate $200 \mathrm{~kW}$ under similar traffic levels, assuming that harvesters are placed under both wheel paths. The CEC study observed that there are considerable differences in the energy output claims made by different vendors, especially with respect to the assumptions made for the number of sensors involved and the traffic level. It was recommended adopting a standardized way of reporting power or energy output by piezo unit surface area, referred to as power or energy density i.e., W/unit area or Wh/unit area, respectively. In evaluating the cost effectiveness of these systems, the CEC report recommended using the "levelized"cost of energy (LCOE) produced by the various harvesting systems varies. The LCOE is defined as the average total life-cycle cost to construct, operate and maintain a power-generating system divided by its total energy output over its service life. This report concludes by recommending further field testing of this technology.

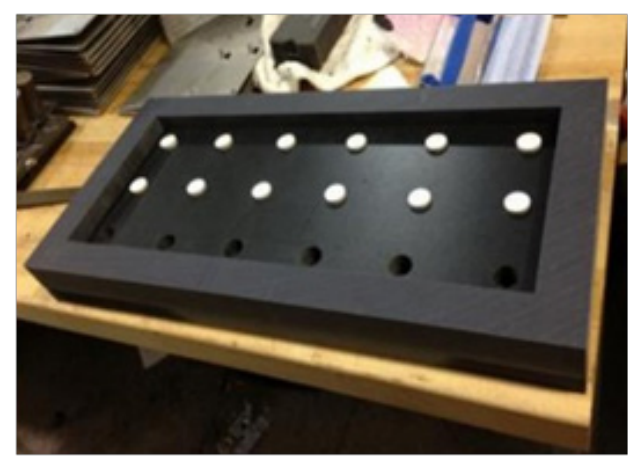

Figure 2 Piezoelectric energy harvesting system developed by Xiong. ${ }^{2}$

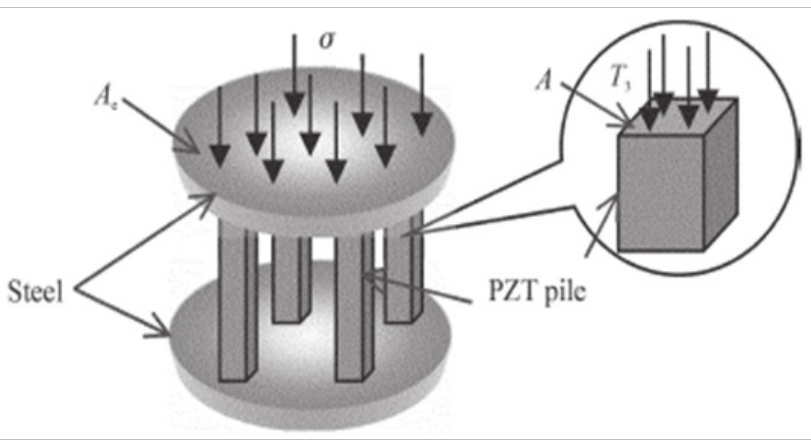

Figure 3 Schematic of PZT Pile Generator ${ }^{4}$

\section{Objective}

The objective of this paper is to further explore the application of piezoelectric technologies for harvesting energy from the action of traffic using the roadways. It provides a brief overview of piezoelectricity fundamentals, a review of the pertinent literature and a preview of our efforts to develop and test several proto types for harvesting energy. The most promising prototype will be refined and integrated into a series of modules laid down in the wheel path of roadways for harvesting energy. They are referred to as the HiSEC Highway Sensing and Energy Conversion modules.

\section{Principles of energy from piezoelectric transduction}

Piezoelectric materials generate electricity when subjected to stress or vibration. They are crystalline ceramics e.g., lead zirconatetitanate, abbreviated as PZT or polymers e.g., polyvinyl fluoride abbreviated as PVF heated above their Curie temperature and subjected to a magnetic field to orient their electric dipoles in the same direction. Stress/strain parallel to the poling direction of a piezoelectric material generates an electrical charge. Conversely, an electric charge generates stress/strain across a piezoelectric material. For simplicity the physics governing piezoelectric power generation are explained below in uniaxial terms i.e., strain/stress in a single direction only. A complete treatment of the subject can be found in the literature. ${ }^{8}$ Consider the piezoelectric element of dimensions $a, b$ and $c$ shown in Figure 4 and assume that the direction of polarization is vertical. A force $F$, parallel to the polarization direction will generate an electrical charge $Q$ (Coulombs) given by:

$$
Q=F d_{33}
$$

Where, $d_{33}$ is the piezoelectric charge constant (Coulombs/N). This mode of loading is referred to as 3-3 loading.

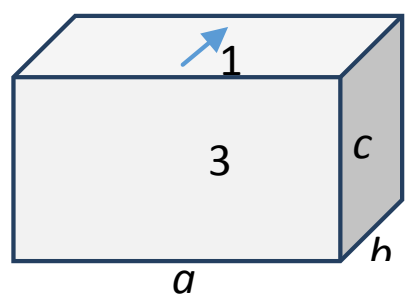

Figure 4 Schematic of a Piezoelectric Element.

Equation 1 can be normalized with respect to the area $A=a b$ as follows:

$$
D=\frac{Q}{A}=\sigma d_{33}
$$

Where $\sigma$ is normal stress $(\mathrm{Pa})$ and $D$ is the charge density (Coulombs $/ \mathrm{m}^{2}$ ), which is related to the electric field $E$ (Volts $/ \mathrm{m}$ ) through:

$$
D=\varepsilon_{0} \varepsilon_{r} E
$$

With $\varepsilon_{0}$ and $\varepsilon_{r}$ the dielectric constant of the air $\left(8.85 \times 10^{-12}\right.$ Farad $/ \mathrm{m}$ ) and the relative (dimensionless) dielectric constant of the piezoelectric material, respectively. Equating Equation 2 and 3 gives: 


$$
\varepsilon_{0} \varepsilon_{r} E=\sigma d_{33}
$$

This reduces to:

$$
E=\sigma g_{33}
$$

Where $g_{33}$ is the piezoelectric constant of the material (Volts $/ \mathrm{m} /$ $\mathrm{Pa}$ ) related to the earlier defined constants through:

$$
g_{33}=\frac{d_{33}}{\varepsilon_{0} \varepsilon_{r}}
$$

The $V$ (Volts) produced from the piezoelectric element of thickness $c$ (Figure 4)is given by:

$$
V=c \frac{F}{a b} g_{33}
$$
tis:

The corresponding electrical power P generated over a time period

$$
P=\frac{V Q}{t}
$$

Which allows computing the energy output by substituting Equ? 1 and 7 into Equation 8 as:

$$
P t=F d_{33} c \frac{F}{a b} g_{33}=d_{33} g_{33}\left(\frac{F}{a b}\right)^{2} a b c
$$

Which integrated over time gives the energy output $W_{33}$ of the piezoelectric sensor as:

$$
W_{33}=\frac{1}{2} \int_{0}^{t} d_{33} g_{33}\left(\frac{F}{a b}\right)^{2} a b c d \xi
$$

Noting that $\frac{F}{a b}$ represents engineering stress, allows expressing Equ. 10 as follows:

$$
W_{33}=\frac{1}{2} d_{33} g_{33} Y^{2} a b c \int_{0}^{t} \dot{o}_{33}{ }^{2} d \xi
$$

Where $Y$ is the Young's modulus and $\dot{o}_{33}$ is the normal strain in direction 3 and $a b c$ is the volume of the element. Equation 11 suggests that the relationship between the strain applied and the amount of electrical energy being generated is non-linear. A similar expression

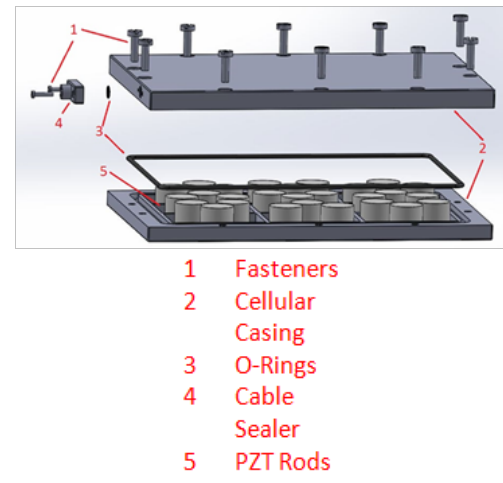

can be derived for a force applied perpendicularly to the direction of polarization i.e., parallel to direction 1 as shown in Figure 4. This is referred as 3-1 loading mode and is denoted by subscripts 31 as opposed to 33 .

\section{Developing the Hisec prototypes}

In developing prototypes for the proposed HiSEC module, various configurations of boxes containing selected number of PZT elements of various shapes were considered. The number of PZT elements included represents a trade-off since the fewer the elements, the higher the stress applied, while the higher the number of elements the higher is the combined power output of the module. The analysis involved FE modeling of the stress distribution inside the boxes, laboratory testing of the power output under load, durability testing under repeated loading and economic feasibility analysis.

\section{Finite element analysis}

The various configurations of the HiSEC prototypes were analyzed using the FE model Abaqus ${ }^{\circledR}$. Key considerations in the development of the prototypes was the stiffness of the box plates, the number of PZT elements included and the way they are arranged to ensure mechanical stability under load. An example of the FE mesh is shown in Figure 5. The FE analysis explored the stresses in the PZT elements, the effect of the stiffness of the box and the effect of the stiffness of the surrounding asphalt concrete pavement. This analysis revealed that the stiffness of the upper side of the box had a marginal effect on the uniformity of the stress distribution in the PZT elements. Furthermore, it determined that for the number and cross section size of the PZT elements considered, the stresses under a moving truck tire are well within the compressive strength range of the PZT elements, which is in the order of $900 \mathrm{MPa} 0 .{ }^{9}$ In addition, buckling of the elements was not an issue for the prototypes analyzed so far under the truck tire service loads anticipated (max dual tire load of $10,000 \mathrm{lbs}$ or $44.4 \mathrm{kN}$ ). Additional stress analysis was conducted to ensure that the boundaries of the box do not cause unduly high strains in the asphalt concrete layer that encapsulates them. A depth of $5 \mathrm{~cm}$ was selected for installing the HiSEC modules, to allow typical asphalt pavement rehabilitation involving milling of the top $5 \mathrm{~cm}$ and overlaying. In addition, statistical analysis was conducted with respect to the width of the HiSEC unit and its optimum lateral placement in the driving lane. It was estimated that a module width of $0.45 \mathrm{~m}$ will suffice to fully support the dimensions of standard dual truck tires, which is approximately $0.5 \mathrm{~m}$. The center of the HiSEC module should be located to maximize the probability of truck tires been located on it. Work by Timm \& Priest ${ }^{10}$ suggests that this should be about $0.80 \mathrm{~m}$ from the edge stripe marking the right hand-side of the driving lane. ${ }^{11}$

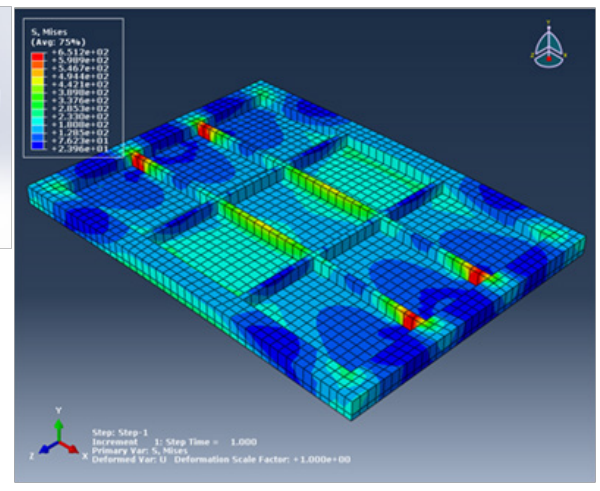

Figure 5 CAD Drawing and Part of the FE Analysis Mesh. 


\section{Laboratory testing of power output}

The HiSEC prototype elements were tested in the laboratory using a $\mathrm{UTM}^{\circledR}$ system. Testing was carried by applying a sinusoidal compressive load at a frequency of $10 \mathrm{~Hz}$ with a peak-to peak magnitude ranging from 0.5 to $3.5 \mathrm{kN}$. Electric power output in the form of Watts Root Mean Square (RMS) was measured directly using a METR Ahit ${ }^{\circledR}$ Watt-meter. In doing so, external resistance $\left(R_{L}\right)$ was added through a resistance substitution box to match the internal resistance $\left(R_{S}\right)$ of each prototype as a function of the loading frequency $f$ applied, using:

$$
R_{S}=\frac{1}{2 \pi c f}
$$

Where, $c$ is the capacitance of each prototype module.

Three of the prototypes tested already are described next, namely prototypes 0, I and IV shown in Figure 6A, 7A, \& 8A, respectively:

I. Prototype 0 is made of 8 PZT elements, each with a diameter of $8 \mathrm{~mm}$ and a thickness of $8 \mathrm{~mm}$. They were sandwiched between two plates of copper of $150 \mathrm{~mm}$ diameter and were loaded through two half sections of a $150 \mathrm{~mm}$ diameter asphalt concrete core.

II. Prototype I is made of 3 layers connected in series each consisting of 25 PZT prismatic elements of rectangular cross section measuring $3.5 \mathrm{~mm}$ by $3.5 \mathrm{~mm}$. Each layer is $11.7 \mathrm{~mm}$ tall and the volume between the PZT elements is filled with epoxy.

III. Prototype II consists of a stack of six cylindrical PZT-5A elements, each with a diameter $44.5 \mathrm{~mm}$ and a thickness of $6 \mathrm{~mm}$, resulting in a cylindrical element of $36 \mathrm{~mm}$ in height. This element is enclosed into a commercially available electrical box.

IV. The laboratory results of the four other prototypes considered had not been completed at the time this paper was prepared. The laboratory results available are plotted for Prototypes 0, I and IV in terms of RMS power $(\mathrm{mW})$ versus the vertical stress applied $(\mathrm{kPa})$ Figures 6B, 7B \& 8B, respectively. These relationships agree with the non-linear form of the energy versus stress/strain suggested by Equ.11. Following this laboratory testing, these prototypes will be subjected to durability testing by embedding them into asphalt concrete samples and subjecting them to repetitive loading from an Asphalt Pavement Analyzer APA.

\section{Economic considerations}

V. The capability of electric power production from these devices was studied using the laboratory obtained curves of power versus stress level highlighted above, i.e., Figures 6B, 7B \& $8 \mathrm{~B}$. For the power production calculations, it was assumed that each HiSEC module measured $0.09 \mathrm{~m}^{2}$ (i.e., 1 foot $\mathrm{x} 1$ foot) and was fitted with the same number of PZT elements used in the laboratory testing that is, 8,25 and 1 , respectively. It is noted that a much higher number of PZT elements can be included per square foot. As mentioned earlier, however, the number of PZT elements will affect the stress applied as well as the combined amount of power being generated.

VI. The traffic volume and composition were considered as variables to the power production analysis. The traffic input assumed for the results presented next is summarized in Table 1 and reflects a moderately busy Interstate highway in the USA. Table 2 shows the calculation steps for the electric power and energy production from the car tires and truck tires expected to pass over a HiSEC module. In doing so, it was assumed that all axles are loaded to the limit and the that the entire load of half the axle in each wheel path is applied to the harvesting module (i.e., all car half-axles applies $1,500 \mathrm{lbs}$ and each truck half-axles applies $10,000 \mathrm{lbs}$ ).

VII. Table 2 suggests that Prototype IV is the best amongst those tested to-date. Under the traffic conditions specified, each Prototype II module can produce up to 241 Watt-hrs per year. This level of energy is low. Its monetary value, at typical commercial rates of about $\$ 0.20-\$-.30 / \mathrm{kWatt}-\mathrm{hour}$, is negligible, where the electric power grid is available roadside. Hence, energy harvesting may be economically feasible only at locations where access to the power grid is not readily available i.e., typical cost of overhead power lines is in the order of $\$ 285,000 /$ mile. On the other hand, the HiSEC modules are particularly attractive for self-contained LED traffic lighting and traffic sensing e.g., traffic volume counting, axle weighing and so on. In effect, a direct HiSEC application would be a lowcost and self-contained weigh-in-motion system. Additional data can be collected, such as strain cycles, temperature and so on.

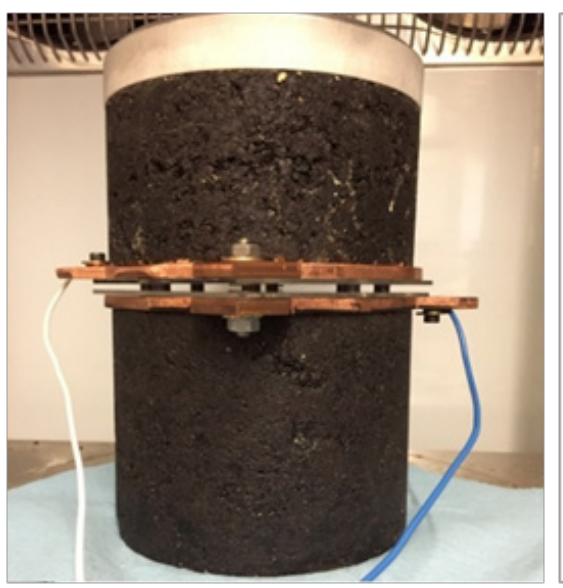

(a)

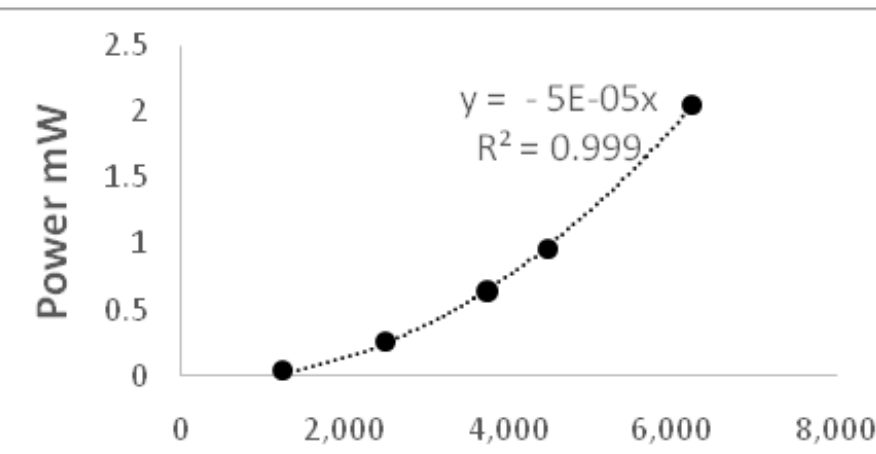

Stress kPa

(b)

Figure 6 Prototype 0: Configuration (a) and RMS Power Output for 8 PZT Units (b). 


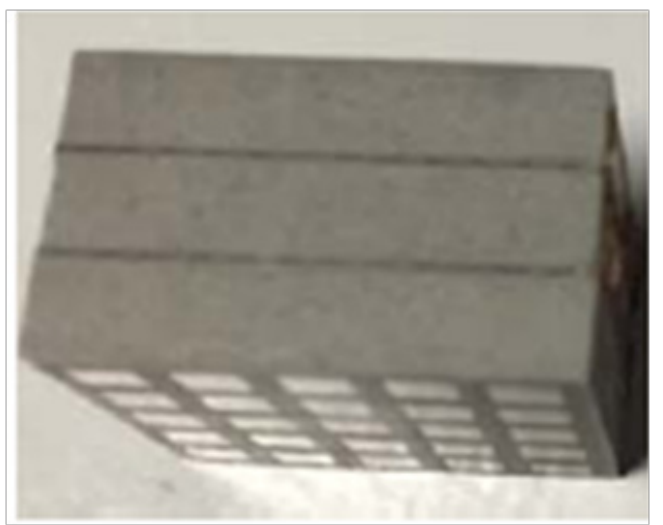

(a)

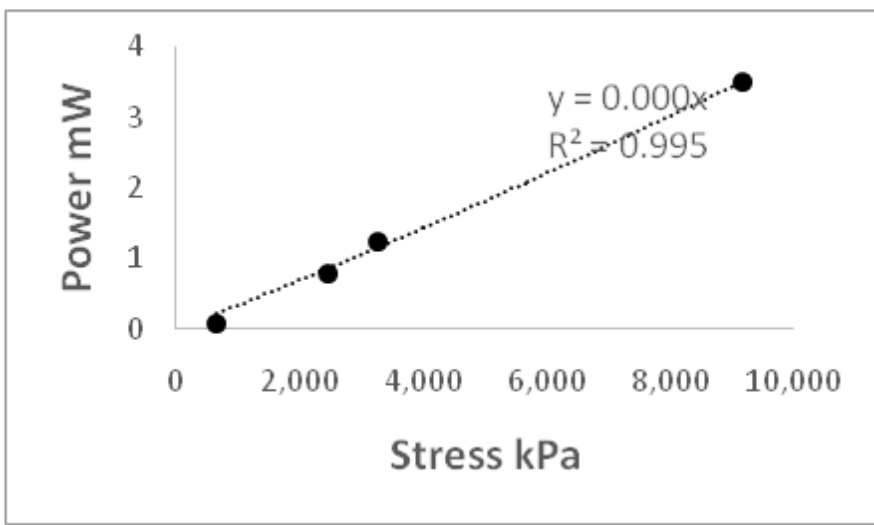

(b)

Figure 7 Prototype I: Configuration (a) and RMS Power Output for 25 PZT Units (b).

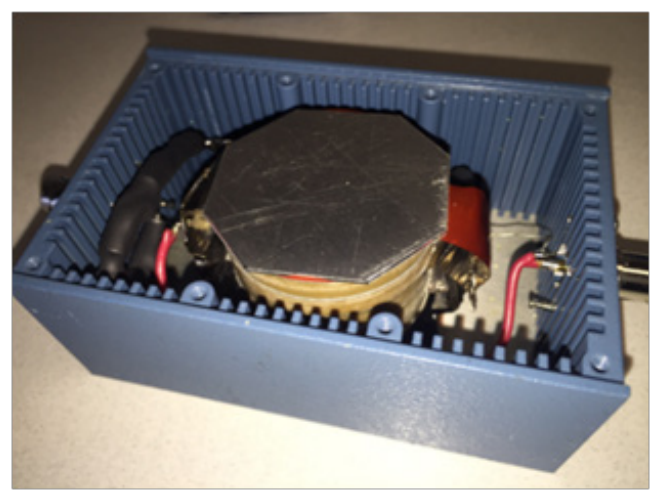

(a)

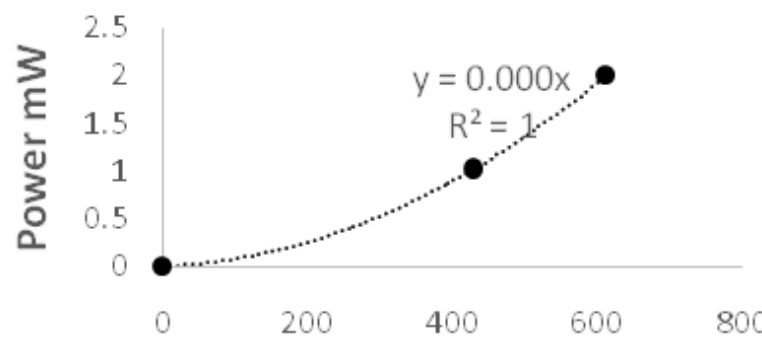

Stress $\mathrm{kPa}$

Figure 8 Prototype II: Configuration (a) and RMS Power Output for a Single Unit (b).

Table I Traffic assumptions

\begin{tabular}{ll}
\hline Traffic property & Value \\
\hline Input & 22.2 \\
\hline Traffic speed $(80 \mathrm{~km} / \mathrm{hr}) \mathrm{m} / \mathrm{sec}$ & 30,000 \\
Average Annual Daily Traffic (AADT) & 4 \\
No lanes & 15,000 \\
AADT/Direction & 25 \\
\hline Percent Trucks in traffic stream & 75 \\
\hline Percent trucks in right Lane & 14,063 \\
\hline Calculated & \\
\hline Number of cars in right lane/day & 2,813 \\
\hline
\end{tabular}

Table 2 Energy output for prototypes I and II under the traffic described in Table I

\begin{tabular}{|c|c|c|c|}
\hline Output & Prototype 0 & Prototype I & Prototype II \\
\hline \multicolumn{4}{|l|}{ Power } \\
\hline $\begin{array}{l}\mathrm{mWatts} / \mathrm{module} / \mathrm{car} \\
\text { tire pass }\end{array}$ & 1.76 & 34.26 & 93.16 \\
\hline $\begin{array}{l}\mathrm{mWatts} / \text { module/truck } \\
\text { tire pass }\end{array}$ & 12.63 & $\mathrm{I}, 560$ & 4,098 \\
\hline \multicolumn{4}{|l|}{ Energy } \\
\hline $\begin{array}{l}\text { Watt-hours/module/ } \\
\text { year from cars }\end{array}$ & 0.08 & 1.58 & 4.30 \\
\hline $\begin{array}{l}\text { Watt-hours/module/ } \\
\text { year from trucks }\end{array}$ & 0.73 & 90.08 & 236.65 \\
\hline $\begin{array}{l}\text { Total Watt-hours/ } \\
\text { module/year }\end{array}$ & 0.81 & 91.66 & 240.95 \\
\hline
\end{tabular}

\section{Summary}

This paper presented preliminary results of the evaluation of several prototype systems for harvesting energy from the action of traffic on roadways. Prototypes were mechanically analyzed using FE, were tested in the laboratory to establish their electric energy generation potential as a function of stress level and were evaluated 
for their financial viability. The results available to date suggest that this technology shows promise in powering warning lights, instrumentation and sensors independently of the power grid.

\section{Acknowledgements}

Funding for this study was provided by the Texas Department of Transportation.

\section{Conflict of interest}

The author declares no conflict of interest.

\section{References}

1. Xiong H. Piezoelectric Energy Harvesting for Public Roadways. Dissertation. USA: Virginia Polytechnic Institute and State University; 2014 .

2. Kim S, Shen J, Ahad M. Piezoelectric-Based Energy Harvesting Technology for Roadway Sustainability. International Journal of Applied Science and Technology. 2015;5(1):20-25.

3. Zhao H, Tao Y, Niu Y, et al. Harvesting Energy from Asphalt Pavement by Piezoelectric Generator. Journal of Wuhan University of Technology. 2014;29(5):933-937.
4. Hill D, Agrawal A, Tong N. Assessment of Piezoelectric Materials for Roadway Energy Harvesting. DNV KEMA Energy and Sustainability. 2013.

5. www.treevolt.com

6. www.genziko.com/technology/road-power-generation/

7. Edel-Ajulay J. Innowattech; Harvesting Energy and Data. Presentation to the $1^{\text {st }}$ International Symposium the Highway to Innovation. Tel Aviv, Israel; 2010.

8. Ertuk A, Inman DJ. Piezoelectric Energy Harvesting. USA: John Wiley and Sons Ltd; 2011.

9. Ewart LM, McLaughlin EA, Gittings KD. Investigation of the Compressive Material Properties of PZT, NUWC-NPT. Technical Report, Naval Undersea Warfare Center Division, Newport RI. USA; 1999.

10. Timm DH, Priest AL. Wheel Wander at the NCAT Test Track. USA: NCAT, Auburn; 2005.

11. Cook-Chennault KA, Thambi N, Sastry AM. Powering MEMS portable devices-a review of non-regenerative and regenerative power supply systems with emphasis on piezoelectric harvesting systems. Smart Materials and Structures. 2008;17(4):1-33. 